
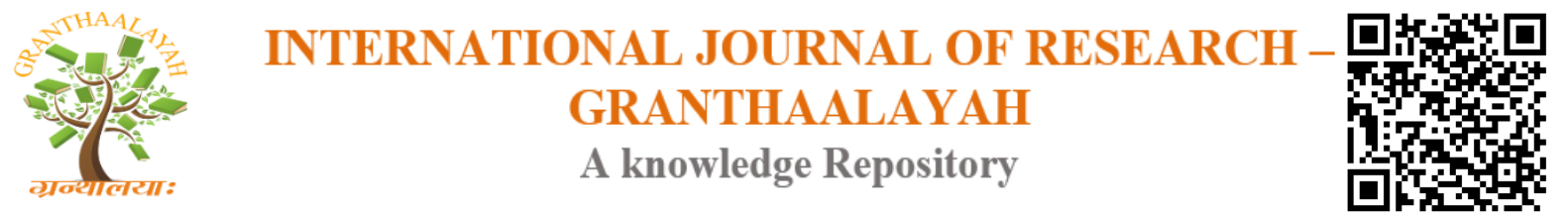

Science

\title{
IMPROVEMENT OF DIELECTRIC STRENGTHS FOR CROSS-LINKED POLYETHYLENE (XLPE) MEDIUM VOLTAGE CABLES
}

\author{
Loai Nasrat ${ }^{* 1}$, Mostafa Ali ${ }^{2}$, Karar Mahmoud ${ }^{1}$ \\ ${ }^{* 1}$ Electrical Power and Machines Eng. Dept., Aswan University, Aswan, Egypt \\ ${ }^{2}$ Upper Egypt Electricity Company, Aswan, Egypt
}

\begin{abstract}
The electricity distribution companies are interested of the types of polymeric materials used in medium voltage cables which is considered the basis of power grid. In this study, it tried to enhance the electrical properties of cross-linked polyethylene (XLPE) after adding inorganic filler: such as Silica (SiO2) filler with $10 \%, 20 \%, 30 \%$ and $40 \%$ concentration percentages. The dielectric strength of the samples was tested under different thermal conditions $(0,25$ and $100 \mathrm{C} 0)$ to simulate different types of environments. Thermal aging is simulated for one week in several temperatures $(70,100$ and $120 \mathrm{C} 0)$ to investigate the effect of variety higher temperature stresses on the electric properties of XLPE in thermal drying oven, after adding Silica filler. Curve fitting is used to choosing the most suitable equation between dielectric strength rates under each thermal condition and variant percentages of Silica filler. It noted that the highest value of dielectric strength for XLPE can be obtained with $30 \%$ percentage of $\mathrm{SiO} 2$ filler [max. at 70 $\mathrm{Co}(30.07 \mathrm{kV} / \mathrm{mm})]$. Polynomial regression by MATLAB code has been adopted to find the proper percentages of $\mathrm{SiO} 2$ filler and the highest value of dielectric strength. This regression algorithm is a form of linear regression where higher order powers $\left(2^{\text {nd }}, 3^{\text {rd }} ..\right)$ of an independent variable are included, and it describes a relationship between an explanatory variable and a response variable.
\end{abstract}

Keywords: Dielectric Strength; XLPE; Silica (SiO2); Degradation; Aging; Polynomial Regression.

Cite This Article: Loai Nasrat, Mostafa Ali and Karar Mahmoud. (2019). "IMPROVEMENT OF DIELECTRIC STRENGTHS FOR CROSS-LINKED POLYETHYLENE (XLPE) MEDIUM VOLTAGE CABLES." International Journal of Research - Granthaalayah, 7(2), 197-206. https://doi.org/10.29121/granthaalayah.v7.i2.2019.1024.

\section{Introduction}

Underground cables are an important part of any power distribution system. These cables are laid in ducts or may be buried in the ground. Unlike in overhead lines, air does not form part of the insulation and the conductor must be completely insulated. This means that the selection of cable must be based on the losses, cost and environmental factors surrounding [1]. One important factor in the safety and reliability of cables is the integrity of their polymeric insulation and jacket materials [2]. 
During production of insulation materials, degradation may be occurred due to the heat which material are exposed. The final manufacture affected by some factors such as plastic type, manufacturing temperature, and the substances used. The output products should be kept at high quality, by eliminate degradation of insulation as much as possible.

XLPE is made from low density polyethylene (LDPE). It is mixed with dicumyl peroxide 4methoxy phenol (3 wt\%) as cross-linked agent in absence of filler to prepare XLPE according to (ASTMF876-10el). To prepare XLPE composites of different ratios (10, 20,30 and $40 \mathrm{wt} \%$ ) of silica $\left(\mathrm{SiO}_{2}\right)$. All samples are tested according to (IEC 60156) for electrical tests.

Polymeric materials used for electrical insulation not only have to exhibit acceptable physical properties but good electrical properties. 01 concerning the so-called charge trapping event in dielectric and insulating materials [3-4].

Power cable aging is affected by different factors some internal due to flowing electricity and external related to the environment. Those factors include intensity of the current, mechanical wiring systems, water and thermal aging. The mechanism of cable aging is mostly carried out in the form of insulating material temperature. The temperature rise accelerates the chemical reaction of the insulator and accelerates the process of insulator deterioration caused by other aging factors [5-6].

The surrounding environment, the operating conditions and the load connected to cable are factors that easily influence the cable. Therefore, the core, insulation layer and its surface will heat. The closer it is to the core, the higher the temperature is. In long-term over-load operation, when the current flowing through the cable exceeds its rated capacity, the temperature of the core will rise abnormally. The aging of the cable insulation material will accelerate under over-heat temperature; insulation breakdown may occur; hence the core temperature should be used as the aging temperature of cable. The cable core temperature is estimated according to the cable actual operation and equivalent environmental temperature [7].

The endurance test was set at high ac field by testing transformer (HV transformer 9105-terco) and at high temperature by aging oven (heraeus-6450hanau), to maximize the stress and minimize the life of the material. All samples were conditioned before the test to remove any impurities or humidity. The least squares technique (regression analysis) used to analysis results by choosing the polynomial that makes the sum of squares of these errors as small as possible.

Regression analysis is a statistical tool for the investigation of relationships between variables. Regression is a statistical technique to determine the linear relationship between two or more variables. Regression is primarily used for prediction and causal inference. In its simplest (bivariate) form, regression shows the relationship between one independent variable (X) and a dependent variable (Y). Regression thus shows us how variation in one variable co-occurs with variation in another, an objective of the software engineering community is that to develop a useful models that are accurately estimates the software effort [8]. Indeed, assembling a single global model can be very difficult. In non-linear regressions, the space is divided into smaller regions, where the interactions are more manageable [9]. 
From this analysis it can recognize the suitable curve or adequate line which introduce the favorite fit of points of the measured data. This curve or line used to clarify the expected direction of data whether it is linear, parabolic, or other form. There are various methods specialist execute regression analysis.

The present work has been devoted to study the effects and the consequences after adding an inorganic filler (silica filler) in XLPE on the electrical performance of cross-linked polyethylene used in medium voltage cables. These effects cab be noted by measuring the dielectric strength of XLPE under several temperatures range tests regard to different weight percentages of filler.

\section{Materials and Methods}

The preparation of XLPE depends on different parameters such as the ratio of XLPE, types and concentrations of filler that effect on properties of the base material and final product. Samples have been prepared in the laboratory of the polymers and pigments department National Research Center (NRC). Polymer composite was prepared by mixing different ratios of Silica filler $(0,10$, 20, 30 and 40 wt. \%). The samples preparation was operated at the room temperature $\left(25^{\circ} \mathrm{C}\right)$, until curing occurred. The experimental setup of dielectric strength in HV laboratory shown in fig (1).

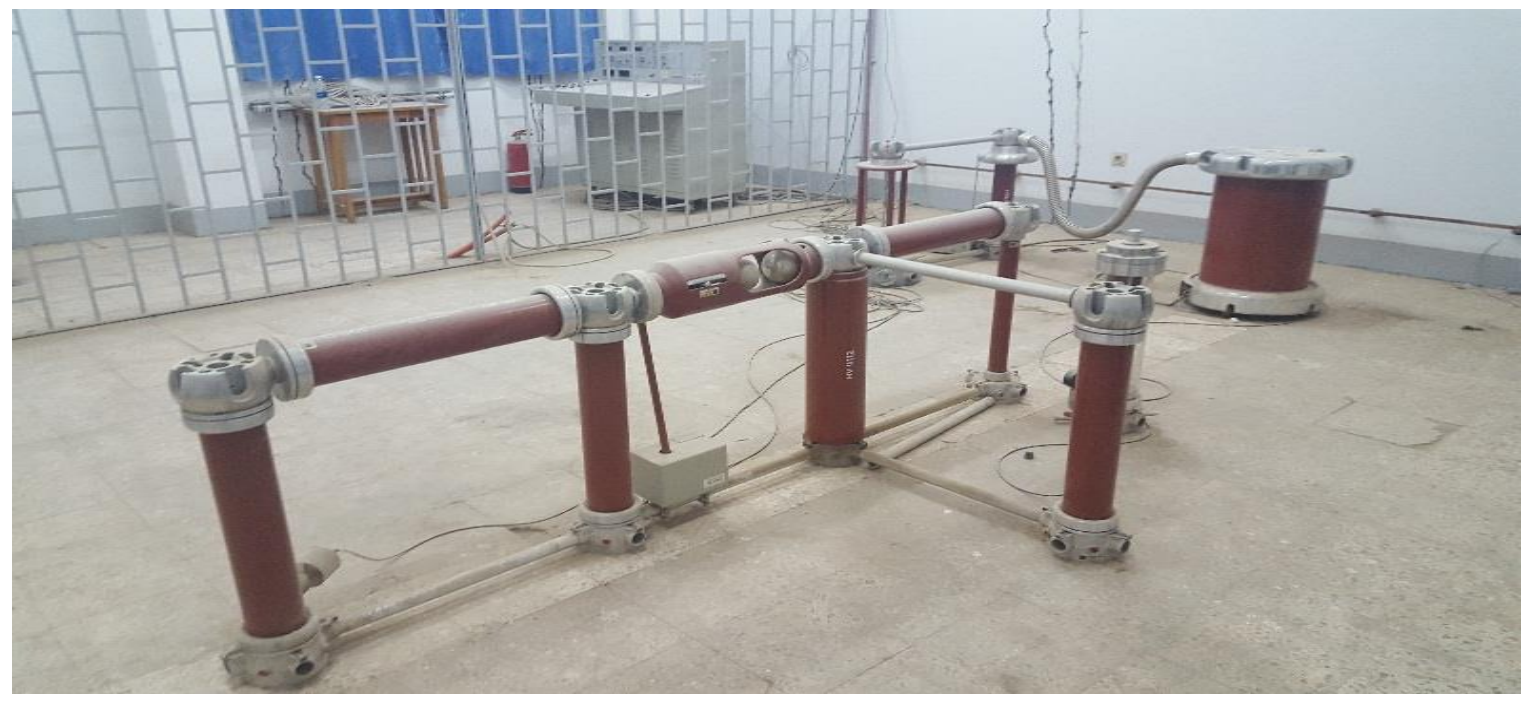

Figure 1: Experimental setup of dielectric strength in the HV laboratory

The dielectric strength test was performed according to the ASTMD149 and IEC6024 standard . The electrodes configuration is two stainless steel cylinders with diameter of $25 \mathrm{~mm}$ at room temperature as shown in Fig (2). The voltage was increased at a rate of $1 \mathrm{kV} / \mathrm{s}$ until breakdown occurs, which is a measure of samples dielectric strengths. For each type of the specimens, 10 pieces of specimens are prepared and tested. The median value of the 10 test results is taken to evaluate the performance of the samples and the odd values are eliminated. 


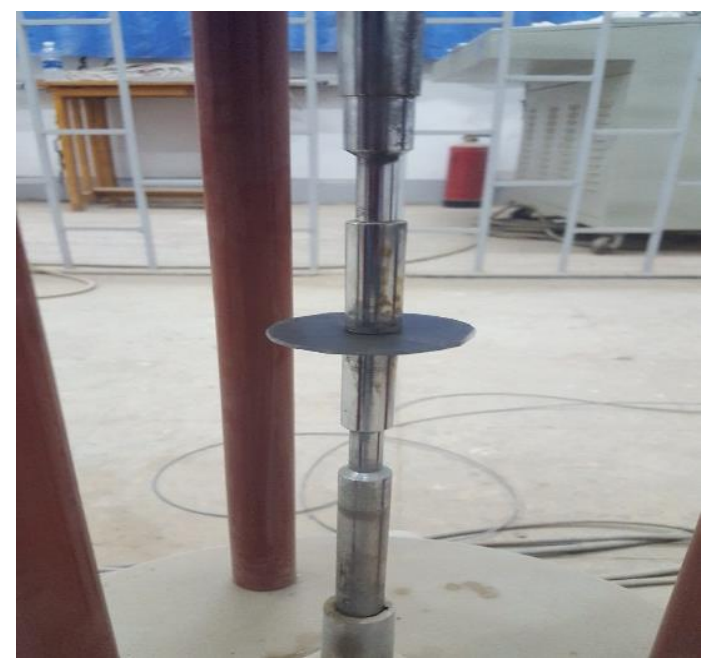

Figure 2: Two stainless steel electrodes consists of supporting arrangements and hand operated gear.

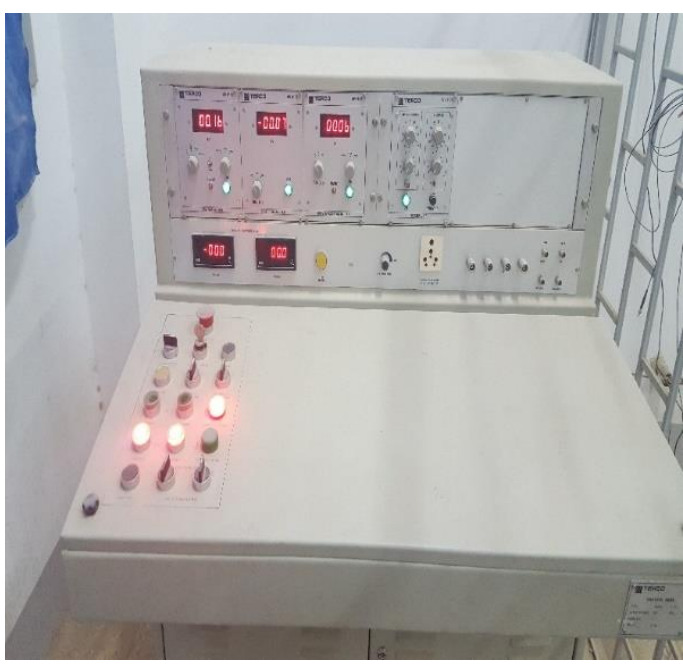

Figure 3: HV 9103 control desk includes measuring instruments and trigger device.

Dielectric strength is calculated by dividing the breakdown voltage by the thickness of the sample. The data is expressed in $(\mathrm{kV} / \mathrm{mm})$ and measured through a circular sample of $1 \mathrm{~mm}$ thickness and $50 \mathrm{~mm}$ diameter.

A higher dielectric strength represents a better quality of insulator, which it tries to get the highest value through this research. The Control desk includes measuring instruments used in our experiments is shown in fig (3).

\section{Results and Discussions}

\subsection{Dielectric Strength Measurements Under Various Temperatures}

Dielectric strength of an insulating material, is the highest value of electric field intensity which the insulator can endure internally without failure of its insulating properties until breaking down of insulator occur. The failure happens when too much current flow through material and fractional devastation occur. It is scientifically agreed that the greater the dielectric strength the greater the efficiency of the insulator.

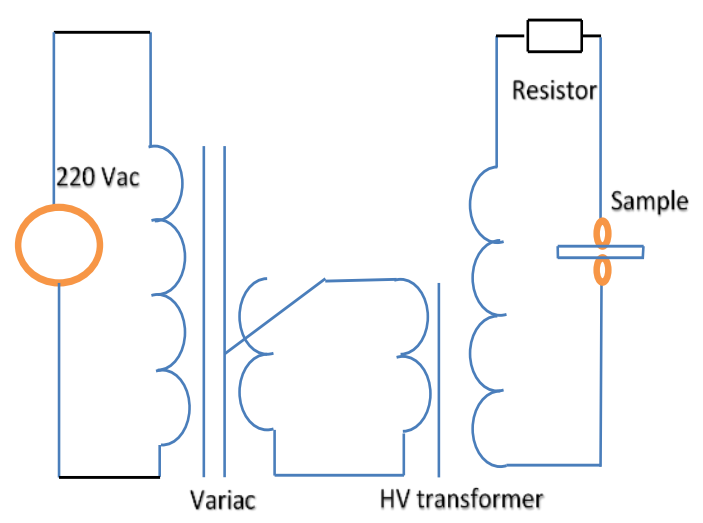

Figure 4: Schematic diagram for dielectric strength testing circuit. 
The dielectric strength of XLPE have been studied under several environment conditions, i.e. : $0^{\circ} \mathrm{C}$, $25^{\circ} \mathrm{C}$ (room temperature) and $100{ }^{\circ} \mathrm{C}$ with different percentages of filler which is $\left(\mathrm{SiO}_{2}\right.$ filler), Fig (4) shows the circuit used for dielectric strength test.

\section{Addition of $\mathrm{SiO}_{2}$ filler}

Average dielectric strength $(\mathrm{kV} / \mathrm{mm})$ for XLPE with different $\mathrm{SiO}_{2}$ filler percentages at variant thermal conditions, i.e. $0{ }^{\circ} \mathrm{C}, 25^{\circ} \mathrm{C}$ (room temperature) and $100{ }^{\circ} \mathrm{C}$ shown in table (1) and drawn in figure (5). It can be noted that the dielectric strength of XLPE was improved by adding $\mathrm{SiO}_{2}$ filler. It can be concluded from the results in table (1) that:

When the $\mathrm{Sio}_{2}$ filler was increased from $10 \%$ to $30 \%$ the value of dielectric strength increased from $22.9 \%$ to $38.8 \%$ compared to XLPE sample without adding any filler percentage.

Then after adding more filler (from $30 \%$ to $40 \%$ ), the value of dielectric strength of XLPE decreased from $38.8 \%$ to $26.8 \%$ compared to XLPE sample without adding any filler percentage.

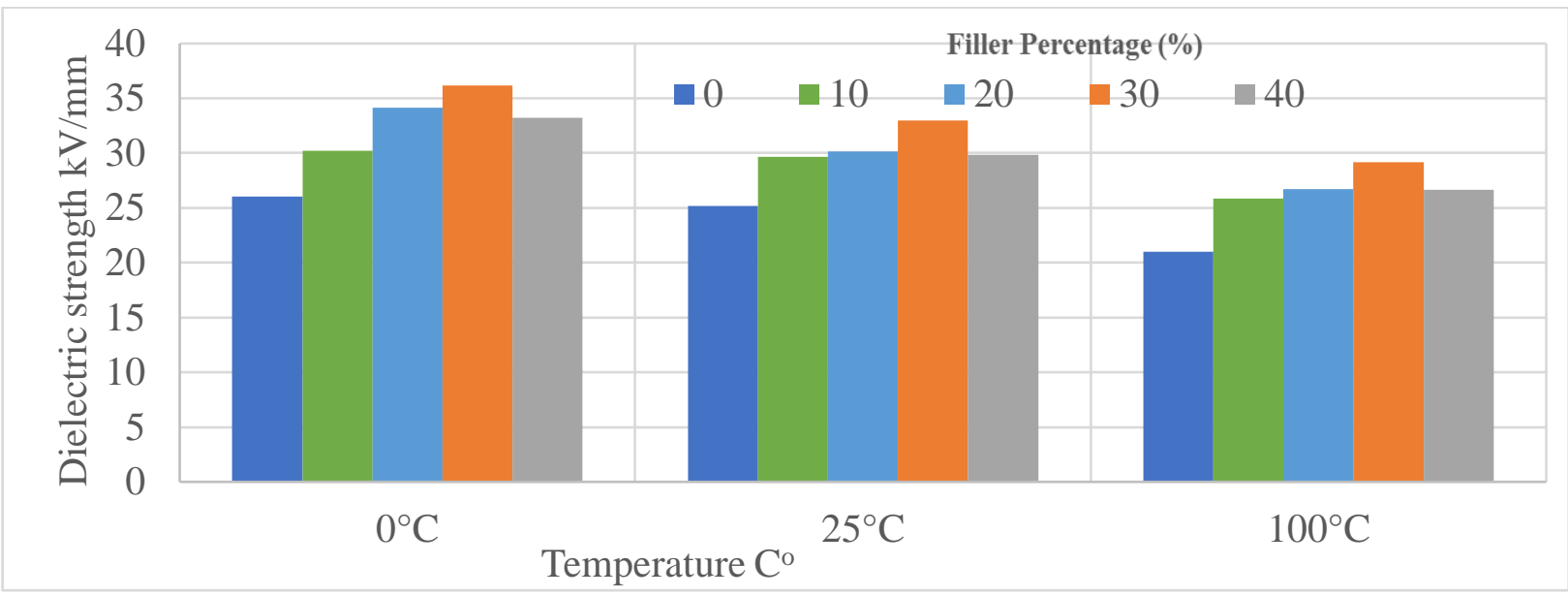

Figure 5: Relation between dielectric strength $(\mathrm{kV} / \mathrm{mm})$ and filler percentages at variant temperature.

Table 1: Average dielectric strengths $(\mathrm{kV} / \mathrm{mm})$ for XLPE with different $\mathrm{SiO} 2$ filler percentages

\begin{tabular}{|c|c|c|c|}
\hline \multirow[t]{2}{*}{$\begin{array}{c}\mathrm{SiO}_{2} \text { filler } \\
\text { percentages }(\%)\end{array}$} & \multicolumn{3}{|c|}{$\begin{array}{c}\text { The average of dielectric strength }(\mathrm{kV} / \mathrm{mm}) \text { at variant } \\
\text { temperature }\end{array}$} \\
\hline & $\mathbf{0}^{\circ} \mathbf{C}$ & $25^{\circ} \mathrm{C}$ & $100^{\circ} \mathrm{C}$ \\
\hline 0 & 26.04 & 25.16 & 21.02 \\
\hline 10 & 30.24 & 29.64 & 25.83 \\
\hline 20 & 34.15 & 30.18 & 26.74 \\
\hline 30 & 36.18 & 32.98 & 29.17 \\
\hline 40 & 33.21 & 29.87 & 26.66 \\
\hline
\end{tabular}

\subsection{Thermal Aging and Dielectric Strength Measurements}

The accelerated thermal aging oven is the most commonly used method for the accelerated thermal aging format [10-11]. It mainly utilizes the rapid heating in the oven to simulate the aging state of the cable insulation material in real usage and compares and analysis the 
characteristic value of life which is highly related with the lifetime [7]. Due to temperature limitation and interval, three aging temperature were chosen, that is $70{ }^{\circ} \mathrm{C}, 100{ }^{\circ} \mathrm{C}$ and $120^{\circ} \mathrm{C}$, where the average dielectric strength $(\mathrm{kV} / \mathrm{mm})$ for XLPE with different $\mathrm{SiO} 2$ filler percentages was measured after the samples were exposed to these aging temperatures for one week, results are shown in table (2) and drawn in fig (6).

Table 2: Average dielectric strengths $(\mathrm{kV} / \mathrm{mm})$ of samples at variant temperatures after one week

\begin{tabular}{|c|c|c|c|}
\hline \multirow{2}{*}{$\begin{array}{c}\mathbf{S i O}_{2} \text { (\%) } \\
\text { (\%) }\end{array}$} & \multicolumn{3}{|c|}{$\begin{array}{c}\text { Average of dielectric strength } \\
\text { temperatures }\end{array}$} \\
\cline { 2 - 4 } & $\mathbf{0}^{\circ} \mathbf{C}$ & $\mathbf{2 5}^{\circ} \mathbf{C}$ & $\mathbf{1 0 0}^{\circ} \mathbf{C}$ \\
\hline 0 & 22.81 & 20.42 & 19.13 \\
\hline 10 & 26.22 & 24.85 & 22.11 \\
\hline 20 & 27.94 & 23.87 & 23.16 \\
\hline 30 & 30.07 & 27.55 & 25.17 \\
\hline 40 & 28.15 & 22.01 & 22.91 \\
\hline
\end{tabular}

After each aging process (168 hrs), samples were placed in the constant room temperature at 25 $\mathrm{C}^{\circ}$, it observed from results that when $\mathrm{SiO}_{2}$ filler percentage increased from $10 \%$ to $30 \%$, the value of dielectric strength increased from $22.9 \%$ to $38.8 \%$ compared to XLPE sample without adding any filler percentage.

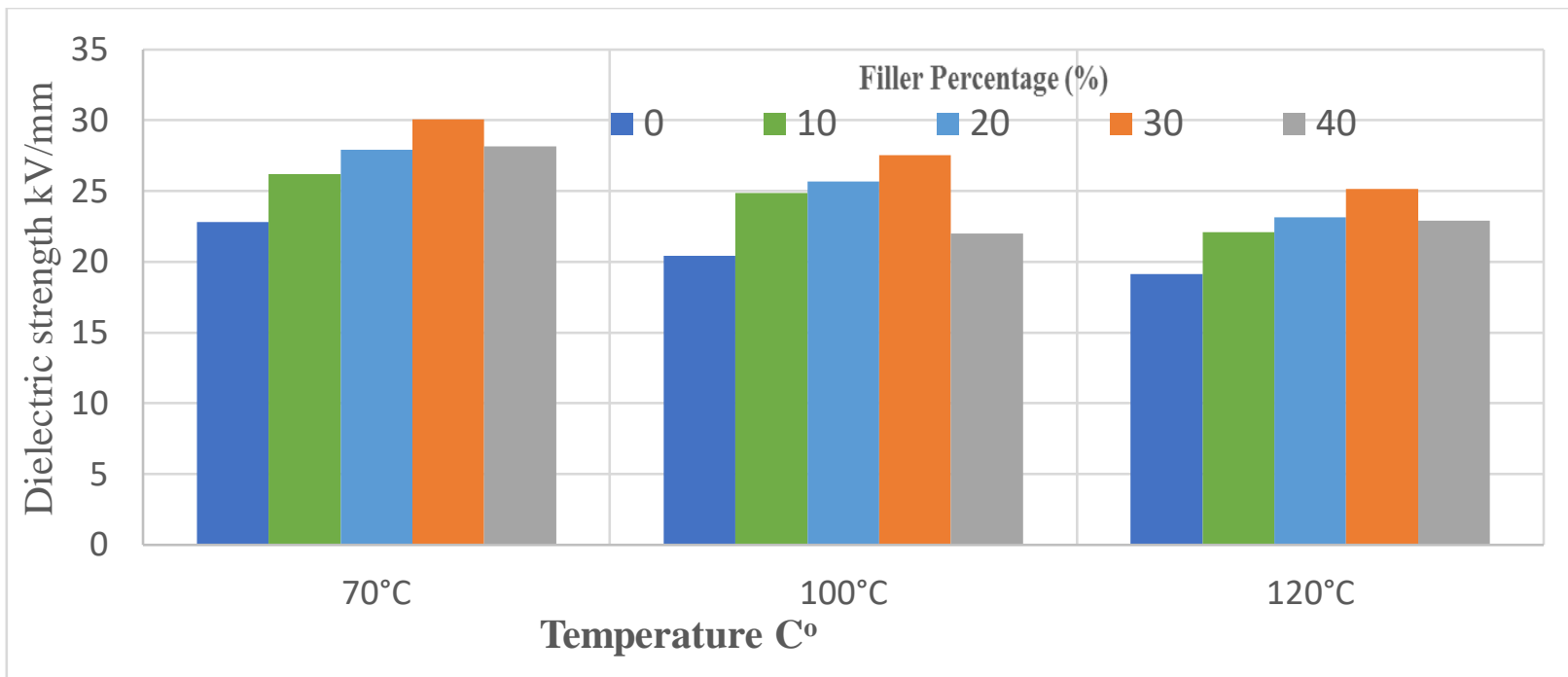

Figure 6: Relation between dielectric strength $(\mathrm{kV} / \mathrm{mm})$ and filler percentages after one week aging.

Applying Curve fitting (polynomial regression analysis) using MATLAB program, the highest curve fitting for the obtained results from the test can be represented by a 3rd degree polynomial equation to minimize the error as possible. It can talk in details about each case of exposing samples to every level of aging temperature for one week as follow: 


\section{At $70{ }^{\circ} \mathrm{C}$ Temperature Level}

The Effect of filler addition on dielectric strength and the observed error between actual and predicted dielectric strength $(\mathrm{kV} / \mathrm{mm})$ after one week aging $70{ }^{\circ} \mathrm{C}$ are shown in table (3) and drawn in fig (7). The equation of curve fitting results of blends at that case, can be determined as follows:

$\boldsymbol{D}_{\mathbf{7 0}}=-0.0001967 \boldsymbol{P}^{3}+0.0044786 \boldsymbol{P}^{2}+0.269 \boldsymbol{P}+22.9$

Where D70 parameter is the dielectric strength value $(\mathrm{KV} / \mathrm{mm})$ at $70{ }^{\circ} \mathrm{C}$ condition, $\mathrm{P}$ is the percentage of concentration of Silica filler in the samples.

Error $_{70}=$ Actual $D S_{70}-$ Predicted $D S_{70}$

Where Error $_{70}$ is the observed error between actual and predicted dielectric strength at $70{ }^{\circ} \mathrm{C}$ (DS70), The method of least squares chooses the polynomial that makes the sum of the squares of these errors as small as possible.

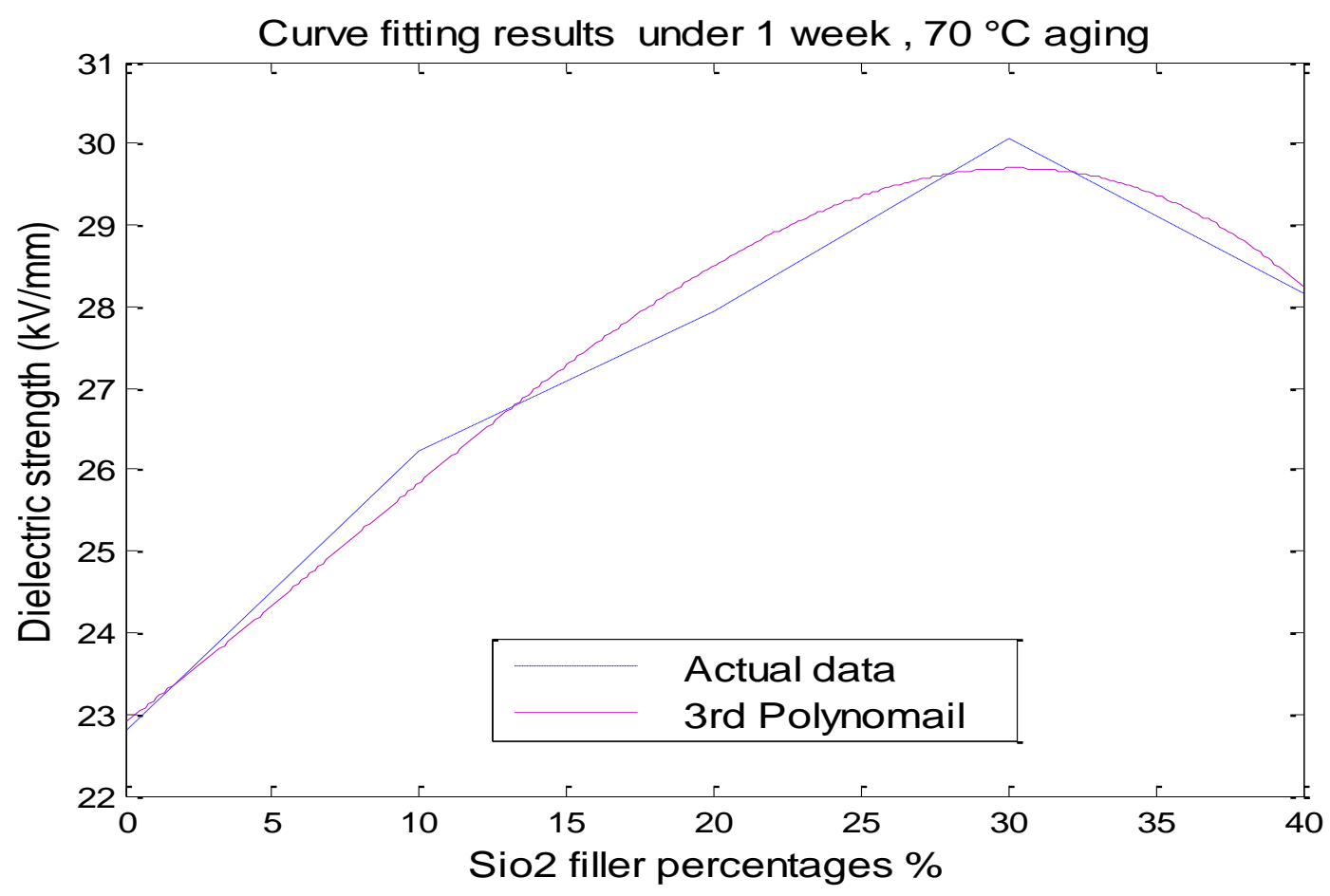

Figure 7: Effect of filler addition on dielectric strength after one week aging $70{ }^{\circ} \mathrm{C}$.

Table 3: Observed error between actual and predicted dielectric strength at $70{ }^{\circ} \mathrm{C}$

\begin{tabular}{|c|c|c|}
\hline $\begin{array}{c}\text { Actual70 dielectric strength } \\
(\mathbf{K V} / \mathbf{m m})\end{array}$ & $\begin{array}{c}\text { Predicted 70 dielectric } \\
\text { strength }(\mathbf{K V} / \mathbf{m m})\end{array}$ & Error 70 value \\
\hline 22.81 & 22.9 & -0.09 \\
\hline 26.28 & 25.84 & 0.38 \\
\hline 27.94 & 28.49 & -0.55 \\
\hline 30.07 & 29.69 & 0.38 \\
\hline 28.15 & 28.23 & -0.08 \\
\hline
\end{tabular}




\section{At $100{ }^{\circ} \mathrm{C}$ Temperature Level}

The Effect of filler addition on dielectric strength and the observed error Error $_{100}$ between actual and predicted dielectric strength $\left(\mathrm{DS}_{100}\right)$ at $100{ }^{\circ} \mathrm{C}$ after one week aging are shown in table (4) and drawn in fig (8). The equation of curve fitting results of blends at that case, can be determined as follows:

$$
\begin{aligned}
& \boldsymbol{D}_{100}=-0.0003175 \boldsymbol{P}^{3}+0.005564 \boldsymbol{P}^{2}+0.3252 \boldsymbol{P}+20.61 \\
& \text { Error }_{100}=\text { Actual } D S_{100}-\text { Predicted } D S_{100}
\end{aligned}
$$

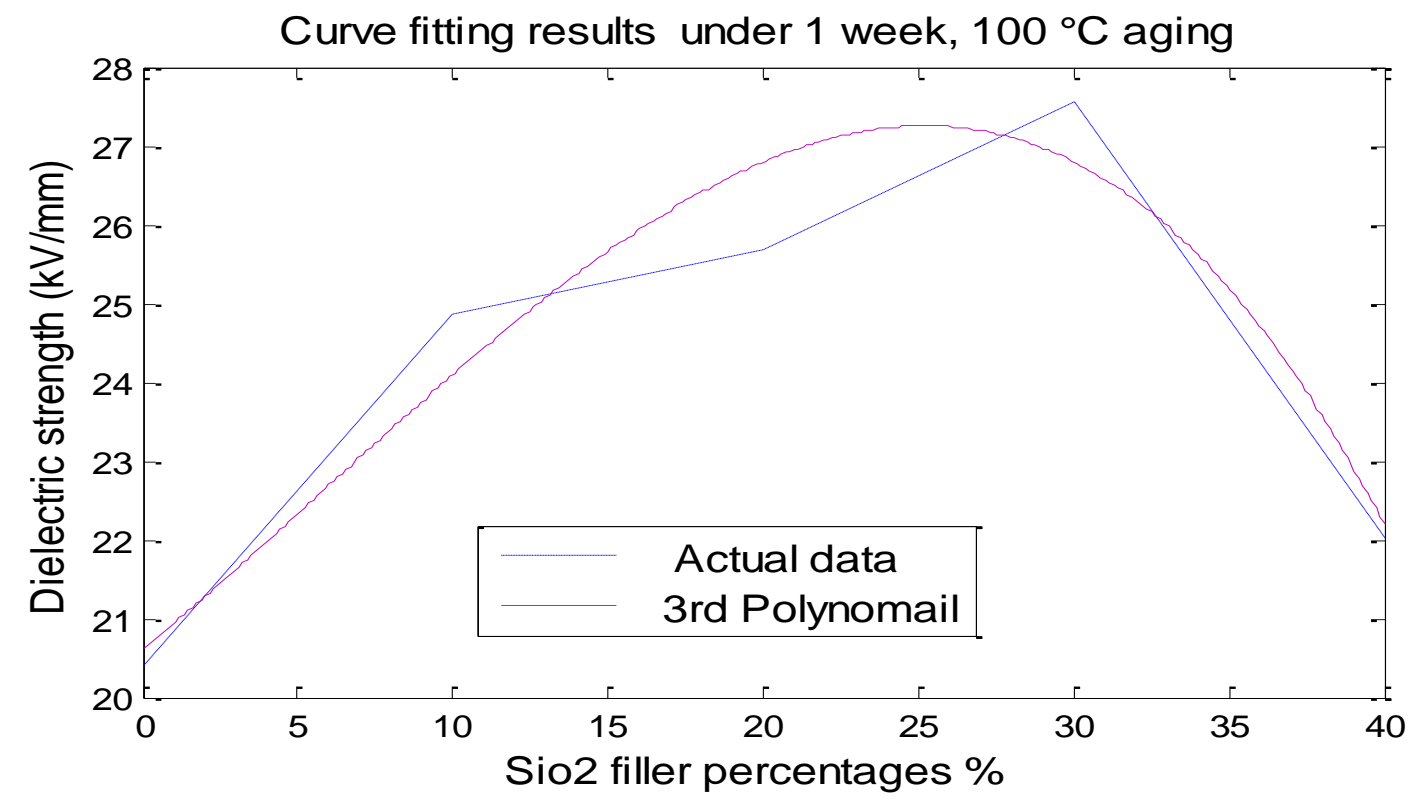

Figure 8: Effect of filler addition on dielectric strength after one-week aging at $100^{\circ} \mathrm{C}$.

\begin{tabular}{|c|c|c|}
\hline $\begin{array}{l}\text { Actual } 100 \text { dielectric strength } \\
(\mathrm{KV} / \mathrm{mm})\end{array}$ & $\begin{array}{l}\text { Predicted } 100 \text { dielectric strength } \\
(\mathrm{KV} / \mathrm{mm})\end{array}$ & $\begin{array}{l}\text { Error } 100 \\
\text { value }\end{array}$ \\
\hline 20.42 & 20.61 & 0.18 \\
\hline 24.85 & 24.1 & 0.75 \\
\hline 25.67 & 26.79 & -1.12 \\
\hline 27.55 & 26.8 & 0.75 \\
\hline 22.01 & 22.19 & -0.18 \\
\hline
\end{tabular}

Table 4: Observed error between actual and predicted dielectric strength at $100{ }^{\circ} \mathrm{C}$

\section{At $120^{\circ} \mathrm{C}$ Temperature Level}

The Effect of filler addition on dielectric strength and the observed error between actual and predicted dielectric strength $\left(\mathrm{DS}_{100}\right)$ at $120{ }^{\circ} \mathrm{C}$ after one week aging are shown in table (5) and drawn in figure (9). The equation of curve fitting results of blends at that case, can be determined as follows:

$D_{120}=-0.000195 P^{3}+0.0049 P^{2}+0.2105 P+19.25$ 


$$
\text { Error }_{120}=\text { Actual } D S_{120}-\text { Predicted } D S_{120}
$$

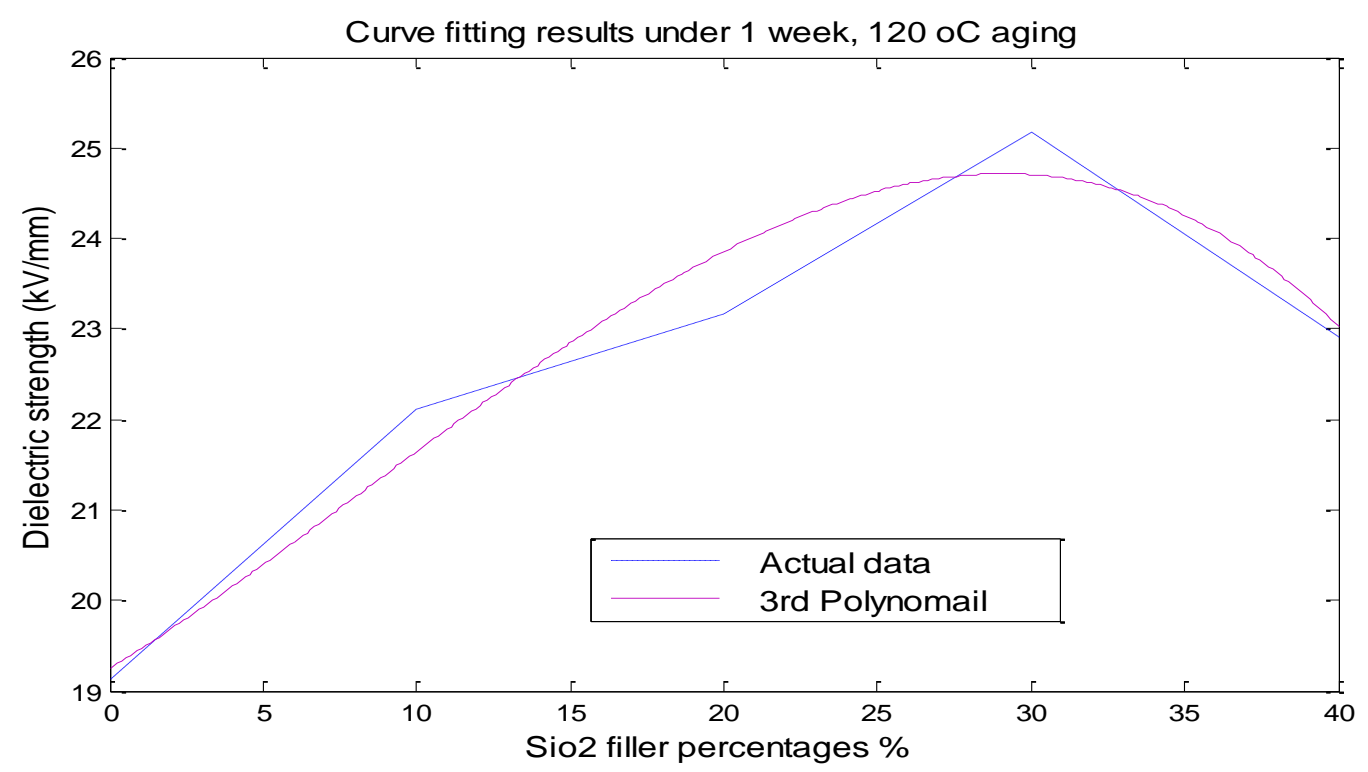

Figure 9: Effect of filler addition on dielectric strength after one-week aging at $120{ }^{\circ} \mathrm{C}$.

Table 5: Observed error between actual and predicted dielectric strength at $120^{\circ} \mathrm{C}$

\begin{tabular}{|l|l|l|}
\hline \multicolumn{1}{|c|}{$\begin{array}{c}\text { Actual 120 dielectric strength } \\
(\mathbf{K V} / \mathbf{m m})\end{array}$} & \multicolumn{1}{|c|}{$\begin{array}{c}\text { Predicted 120 dielectric strength } \\
(\mathbf{K V} / \mathbf{m m})\end{array}$} & $\begin{array}{c}\text { Error 120 } \\
\text { value }\end{array}$ \\
\hline 19.13 & 19.25 & -0.12 \\
\hline 22.11 & 21.65 & 0.46 \\
\hline 23.16 & 23.85 & -0.69 \\
\hline 25.17 & 24.71 & 0.46 \\
\hline 22.91 & 23.03 & -0.12 \\
\hline
\end{tabular}

It was observed from the previous three cases, that dielectric strengths gradually increased with increasing the $\mathrm{SiO}_{2}$ filler percentage until definite value, then it was decreased. This is due to the saturation that happened in the lattice of XLPE and the more addition of $\mathrm{SiO}_{2}$ filler to XLPE made the composites brittle so dielectric strength decreased, and due to increasing flow of leakage current that increases the opportunity of break down to occur.

\section{Conclusions and Recommendations}

From this study, It can be noted that suitable addition of $\mathrm{SiO} 2$ filler had resulted some improvement in the electrical properties of XLPE, where the dielectric strength of XLPE was improved. Without thermal aging, the highest value of dielectric strength for XLPE can be obtained with 30\% percentage of $\mathrm{SiO}_{2}$ filler [max. at $\left.0 \mathrm{C}^{\mathrm{O}}(36.18 \mathrm{kV} / \mathrm{mm})\right]$.After the exposure of samples for one week (168 hrs) thermal stress, the highest value of dielectric strength for XLPE can be obtained with $30 \%$ percentage of $\mathrm{SiO}_{2}$ filler [max. at $\left.70 \mathrm{C}^{\circ}(30.07 \mathrm{kV} / \mathrm{mm})\right]$.Suitable percentages of $\mathrm{SiO}_{2}$ filler must be added to XLPE, where more addition of filler lead to decreasing of XLPE dielectric strength, the decreasing of XLPE dielectric strength may be understood that exposing the samples to different high temperatures for long period lead to changing the physical structure of samples and it became 
more rigid than before where color start to change and composite bonds starting to broke. Finally, it recommends that $\mathrm{SiO}_{2}$ filler is suitable for application of XLPE underground cables used in electricity companies for medium voltage cable (11 kV up to $66 \mathrm{kV})$.

\section{Acknowledgements}

The authors would like to thank the staff of High Voltage Laboratory and National Research Center, Polymers and pigments department, where most of the samples preparation and experimental work were carried out.

\section{References}

[1] A.S Pabla, Electric Power Distribution, United States, 2005.

[2] N. Bowler, S. Liu, Aging Mechanisms and Monitoring of Cable Polymers, International Journal of Prognostics and Health Management, 2015, 1-12.

[3] Boris Lon car,Sasa Ko cinac, Radiation Effects and Defects in Solids, 167 (12), 2012,903-912.

[4] N. Hussin, G. Chen, Analysis of Space Charge Formation in LDPE in the Presence of Crosslinking Byproducts, IEEE Transactions on Dielectric and Electrical Insulation,19 (1) ,2012, 126-133.

[5] W. Choo, G. Chen, S.G. Swingler, Electric field in polymeric cable due to space charge accumulation under DC and temperature gradient, IEEE Transactions on Dielectric and Electrical Insulation.18 (2), 2011,596-606.

[6] A. Levet, J. Colombani, L. Duponchel,Studying Radiolytic Ageing of Nuclear Power Plant Electric Cables with FTIR spectroscopy, Talanta (172),2017,139-146.

[7] Z. Zhang, P. Dieu Seul Assala, Lihao Wu.Residual Life Assessment of $110 \mathrm{kV}$ XLPE Cable. China,January 2018,1-9.

[8] Zhiwei $\mathrm{Xu}$, and T.M.Taghi M. Khoshgoftaar, Identification of Fuzzy Models of Software Cost Estimation, Journal of Fuzzy Sets and Systems, Volume 145, Issue 1, 2004, 141-163.

[9] M. Karar,M. Abdel-Nasser, Efficient SPF Approach Based on Regression and Correction Models for Active Distribution Systems. IET Renewable Power Generation, 11(14) ,2017,1778-1784.

[10] L.R. Vollaro, J. Fontana, A. Vallati, Thermal Analysis of Underground Electric Power Cables Buried in Non-homogeneous Soils, Appl. Therm. Eng. 31 ,2011, 772-778.

[11] M. Ekelund, P.F. Fantoni, U.W. Gedde,Thermal Ageing Assessment of EPDM-chlorosulfonated Polyethylene Insulated Cables Using Line Resonance Analysis,(LIRA), Polym. Test. 30 , 2011, 8693..

*Corresponding author.

E-mail address: loaisaad @yahoo.com 